\title{
A Study on Linking High-school Physics and Perfect Teaching Reformation of College Physics
}

\author{
Xiaolai Liu \\ College of Science, Beijing University of Chemical Technology \\ Beijing 100029, China \\ Qun Li \\ Inner Mongolia research department of education \\ Jiangtao Gao (Corresponding author) \\ The High School Affiliated to Renmin University of China \\ Haidian district, Beijing, China
}

Received: July 22, 2010 Accepted: August 24, 2010 doi:10.5539/hes.v1n1p121

This paper is funded by the College Education Reform Project of Beijing University of Chemical Technology (B60849).

\begin{abstract}
For the students who have just entered colleges, learning university physics would be a challenge. This paper discusses how to make students who have just finished senior high school physics won't feel difficult in learning university physics and how to guide and cultivate the students' interest in the study of physics so to stimulate the students' initiative to explore physics. The paper also attaches importance to the combination of high school physics and conducting teaching reform in college physical courses providing an effective way to solve the above question. This paper discusses the necessity of teaching reform in college physics teaching and the use of material and methods based on consideration of joining senior high school physics, attempting to find a breaking through the traditional single direction teaching mode, which can cultivate talents to analyze and solve problems with innovative quality.
\end{abstract}

Keywords: Teaching reformation, College physics, High-school physics, Linking

In recent years, building China into a powerful nation in the field of higher education and reforming college physics teaching have become a concerned topics among China's college physical circle. And they have done a lot research on the teaching contents, methods and tools (Long Yaojun, 2006; Tao Hongwen, 2004).

In China, the Basic Requirements of physical teaching in science and engineering colleges requests that physical teaching for college students should play an important role in helping the students acquire necessary physics knowledge, enhance their ability to analyze and solve problems, and cultivate the students' exploring spirit and innovation consciousness. The teaching process should be an interaction and communal development between teachers and students. The relationship between imparting knowledge and cultivating ability should be focused and managed during the teaching process. The students' independence and autonomy should be paid great attention. What's more, the teacher should guide the students to learn by questioning, investigation, and exploration. Therefore, the learning process can become an active, and characteristic process under teachers' guidance. Physical teaching reform in colleges is a new kind of improvement with the teacher as supervisor and the student as the main body, interacting and macimuming the students' subjective initiatives. Physical teaching reform is also an effective way to realize the above requirements.

\section{The Necessity of Researching on the Linking of High-school Physics within the Context of College Physics Teaching Reformation}

For the students who have just entered science and engineering college, learning university physics will bring them 
much inadaptation, among which is college physical teaching has more teaching content and less teaching hours than senior high school. Hence, there are not so much time available for practice. As a result, the college physical teachers have to use the main teaching method: cramming education, while the students copy the board writing passively and just listen the teachers' word without thinking, questioning and discussing the teaching mode is in single direction. A widely coverage of survey results shows that (Qi Xin, 2007): a hundred percentages of students feel that college physics is difficult. Almost all students consider that physics is difficult to learn. With the deepening of the content, more and more students were left behind schedule and see physical a heavy stuff. They said they did not know what the teachers said and were tired of physics, even resist learning physics. According to the author's scientific research and teaching work experience, innovative thinking and the ability to analyze and solve problems are built on theoretical foundation. It's hard to imagine that one student can learn his course well if he loses interest even has boredom emotions caused by learning difficulty.

The author has done some research and discussion in how to inspire student's interest, guide students' autonomous learning and stimulate their initiative in learning university physics during the process of conducitng education reform at different levels (Gao Yuan \& Zhou Jiping, 2007), and found that in high school teaching in China has already introduced research teaching methods, which was several years earlier than the university. The senior high school physics teaching syllabus in China explicitly pointed out that: The teacher should adopt a teaching method which encourage the students to participate, explore and make them diligent in thinking. The teacher should arouse the students' learning interest, making them actively acquire knowledge and improve ability. Necessary discussions should be carried out, which can make the learning process lively. The students' aptitude and the actual situation should be taken into consideration, so that the students can learn and development actively and effectively. The teachers do not need to give the students too many details during the classes. On the contrary, they should give the students spaces to think and explore. The teacher should guide the students to master of the correct way of learning, learn to read textbooks, and learn to summarize knowledge and methods (Tao Hongwen, 2004; Wang Yun, Li Changjiang \& Liu Xiaolai, 2002).

According to the author's experience, at least $60 \%$ of all the students do not feel difficult in physics in senior high school and they are interested in physics. When asked this question: why aren't they interested in physics anymore? The universal answer of freshman and sophomore is as follows: there are some cohesion problems between high school physics and college physics. The author has the same feeling during the past teaching time. Therefore, how to make the students who have finished senior high school to learn college physics much easier and how to guide and cultivate the students' interest in study of physics? While introducing the research-based teaching method to college physics provides an effective way to solve the above problem, which also injects fresh vitality to the traditional teaching mode.

\section{The Linking of Teaching Content between High-school Physics and College Physics}

College physics teaching reform requires that the function of teacher should be changed from "lecturer" to "guider", which is a higher request for teachers. The teachers should create questions concerned closely with materials. The two factors - teachers and students should be taken into full consideration when establishing questions. Teachers should shoot the arrow at the target while raising questions ingeniously according to the textbooks of basic concepts and principles. They are required to guide the students to reflect and discuss, so to help them to learn actively and cultivate their scientific research spirit. But not all of the contents is suitable for research-based teaching, which requires the teachers to pay more attention to the linking between senior high school and college physics, and have an adequate understanding of course content system and students' knowledge.

The structure and content of high school physics have undergone some changes, because of the senior high school physics teaching reform, and different regions have different situations. While the college physics course based on the junior and senior high schools is systematic and has strong consistency. So during the course of college physics, especially research-based teaching, the teachers should not only have a profound master of college physics content, but should also know senior high school teaching and the students' study situation so to facilitate the linking between high school physics and university physics and make the teacher have a better understanding of research-based teaching materials. Take the thermodynamic parts as an example, the first law of thermodynamics, the law of conservation of energy, the second law of thermodynamics and etc are compulsory content in senior high school physics. While in college physics, the first thing we do is to let the students understand some basic concepts such as static process and then we will deal with the equivalent process, adiabatic process, cyclic process etc. Meanwhile, combing with examples from scientific research, we can raise suitable questions and requests. This teaching method is fruitful and conductive. 


\section{The Linking of Teaching Methods between High-school Physics and College Physics}

Technically, some physics teachers still adopt traditional method of interpretation. Some new methods such as discussion, exploration and the experimental testing method are rarely used. They do not pay enough attention to the updating of teaching methods and the cultivation of the students' ability. On the contrary, they put stress on the completeness and systematic knowledge. They focus on samples and calculating skills, and on examination, which left small space for students. Sometimes, the courses in colleges are very similar to the one in senior high schools. The author has conducted some surveys on science and engineering students who have learnt college physics. Very few students knew physical thoughts and methods. Some said it was experiment, while some others had no idea about that. Although information society has coming, a number of teachers are unable to use multimedia facilities for teaching, let alone using their own creative multimedia courseware to aid teaching. There are quite many teachers who still use the traditional teaching mode with chalk and blackboard. Of course, many teachers can carry on the teaching process with multimedia, but still stay in the primary stage of projection which is far away from modern industrial approaches.

Teaching innovation reform in college physics is a new teaching mode with teachers as the supervisor and students as the main body. It has been known that students has more or less familiar with research-based methods in secondary school according to the senior high school physical teaching syllabus (Gao Yuan \& Zhou Jiping, 2007; Zhang Hongtian, Meng Shangjiu, Qin Jinping \& Guo Xiuying, 2006). During the process of college physical teaching, teachers should not only know the contents of senior high school physical and grasp the material of research-based teaching, but also know physical teaching methods in senior high school. They are supposed to attach importance to students' status in learning process of college physics. They should, adopt various flexible interactive teaching methods, guiding and exerting students' initiative so as to make the students actively to learn, think and summarize.

\section{The Linking of Teaching Tools between High-school Physics and College Physics}

Some discussion on college physics teaching reform has been done by our university. With full understanding of textbooks and students, the teachers choose materials which are suitable to research-based teaching reform and implement elicitation teaching method. The students are divided into three groups in each class. The class are conducted by three steps in general. First, students are asked to read textbooks, summarize data and answer questions. Then they are guided to discussion and communication in groups. Last, one student will be chosen as a delegate and to exchange ideas with others. Take the first law of thermodynamics, four typical thermodynamics process and circulatory process as an example, these contents look easy. Students have learnt the first law of thermodynamics, so it is difficult for the teachers to activate the students' initiative. Our method to handle this section is as follows. After lecturing on each parameter, reactive calculation and Moore conception, we will raise certain difficulty problems basing on each typical thermodynamics process and recycling process. According to the above steps, students are required to answer the questions, summarize and discuss in groups. Finally, each group chooses a representative to explain the questions. After finishing all these process, teachers need to make evaluation and clarify the key points and difficult points.

\section{Conclusions}

College physics teaching have been advocating avoiding traditional exam-oriented education, and paying attention to quality-oriented education which can cultivate the students ability on acquiring knowledge, analyzing problems and addressing problems. And teaching reform helps us to change educational ideas and provides a new way to operate quality-oriented education.

Reform in college physical teaching puts forward higher request to teachers undoubtedly. We should not only improve our scientific quality, but also pay attention to the interface with high school physics. We also need to have a general idea of the the teaching content and teaching methods of high school physics. At the same time, careful research of the teaching materials, in-depth understanding of the students, full grasp of the teaching content, advanced and practical teaching methods, and the leading role of teachers are also very important. On the other hand, guiding the students to study independently, stimulating the enthusiasm of students to study physics, laying necessary physical foundation for students, strengthening the students' ability of analyzing and solving problems, and developing the students' spirit of exploration and innovation awareness are also very necessary. In order to realize the above aspects, first, we should make students master the basic concepts, laws and methods of physics with teacher-student interaction and group discussion. Secondly, we should create an environment, in which the students can experience the academic atmosphere of research, and develop good scientific style. 


\section{References}

Qi Xin. (2007). Changjiang, Li \& Xiaolai, Liu. Collected papers of college physical courses.

Long Yaojun. (2006, 3). The value reflection and connotation interpretation in college research-based teaching. College education in China.

Tao Hongwen. (2004, 4) Hubei Normal University Journal.

Gao Yuan \& Zhou Jiping. (2007, 12). College education in China.

Zhang Hongtian, Meng Shangjiu, Qin Jinping \& Guo Xiuying. (2006, 12). China higher education Research.

Wang Yun, Li Changjiang \& Liu Xiaolai. $(2002,8)$. Journal of Chongqing Universtiy. 